\title{
Thermal Stress Analyses for an NLC Positron Target with a 3mm Radius Beam
}

W. Stein, A. Sunwoo, J.C. Sheppard, V. Bharadwaj, D. Schultz

August 28, 2002

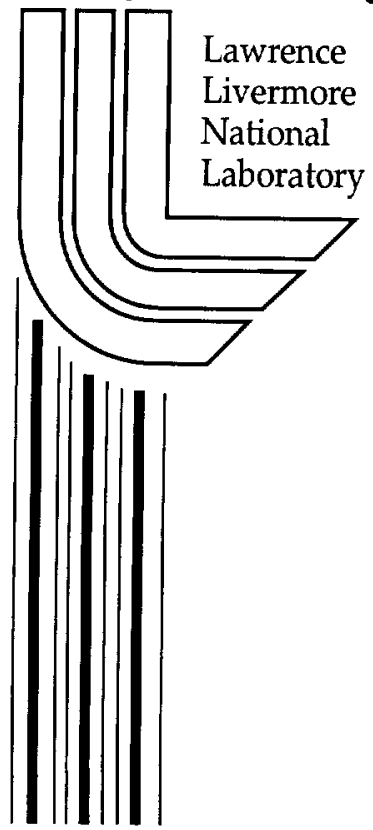




\section{DISCLAIMER}

This document was prepared as an account of work sponsored by an agency of the United States Government. Neither the United States Government nor the University of California nor any of their employees, makes any warranty, express or implied, or assumes any legal liability or responsibility for the accuracy, completeness, or usefulness of any information, apparatus, product, or process disclosed, or represents that its use would not infringe privately owned rights. Reference herein to any specific commercial product, process, or service by trade name, trademark, manufacturer, or otherwise, does not necessarily constitute or imply its endorsement, recommendation, or favoring by the United States Government or the University of California. The views and opinions of authors expressed herein do not necessarily state or reflect those of the United States Government or the University of California, and shall not be used for advertising or product endorsement purposes.

This work was performed under the auspices of the U.S. Department of Energy by the University of California, Lawrence Livermore National Laboratory under Contract No. W-7405-Eng-48.

This report has been reproduced directly from the best available copy.

Available electronically at http://www.doc.gov/bridge

Available for a processing fee to U.S. Department of Energy

And its contractors in paper from

U.S. Department of Energy

Office of Scientific and Technical Information

P.O. Box 62

Oak Ridge, TN 37831-0062

Telephone: (865) 576-8401

Facsimile: (865) 576-5728

E-mail: reports@adonis.osti.gov

Available for the sale to the public from

U.S. Department of Commerce

National Technical Information Service

5285 Port Royal Road

Springfield, VA 22161

Telephone: (800) 553-6847

Facsimile: (703) 605-6900

E-mail: orders@ntis.fedworld.gov

Online ordering: http://www.ntis.gov/ordering.htm

\section{OR}

Lawrence Livermore National Laboratory

Technical Information Department's Digital Library

http://www.llnl.gov/tid/Library.html 
UCRL-ID-

\title{
THERMAL STRESS ANALYSES FOR AN NLC POSITRON TARGET WITH A 3 mm SPOT RADIUS BEAM
}

\author{
Werner Stein \\ Anne Sunwoo \\ John C. Sheppard \\ Vinod Bharadwaj \\ David Schultz
}

August 28, 2002

This work was performed under the auspices of the U. S. Department of Energy by the University of California, Lawrence Livermore National Laboratory under Contract No. W-7405-Eng-48 and by the Stanford Linear Accelerator Center under Contract No. DEAC03-76SF0051 


\title{
Thormal Stress Analyses for an MLe Positron Taryot with a $3 \mathrm{~mm}$ Spot Radius Boam
}

\author{
Werner Stein*, Anne Sunwoo*, John Sheppard** \\ Vinod Bharadwaj**, and David Schultz**
}

\author{
*Lawrence Livermore National Laboratory, Livermore, California \\ **Stanford Linear Accelerator Center, Stanford, California, 94309 USA
}

\begin{abstract}
The power deposition of an incident electron beam in a tungsten-rhenium target and the resultant thermal shock stresses in the material have been modeled with a transient, dynamic, structural response finite element code. The Next Linear Collider electron beam is assumed split into three parts, with each part impinging on a 4 radiation lengths thick target. Three targets are required to avoid excessive thermal stresses in the targets. Energy deposition from each beam pulse occurs over 265 nanoseconds and results in heating of the target and pressure pulses straining the material. The rapid power deposition of the electron beam and the resultant temperature profile in the target generates stress and pressure waves in the material that are considerably larger than those calculated by a static analysis. The $6.22 \mathrm{GeV}$ electron beam has a spot radius size of 3 $\mathrm{mm}$ and results in a maximum temperature jump of $147^{\circ} \mathrm{C}$. Stress pressure pulses are induced in the material from the rapid thermal expansion of the hotter material with peak effective stresses reaching $83 \mathrm{ksi}\left(5.77 \times 10^{8} \mathrm{~Pa}\right)$ on the back side of the target, which is less than one half of the yield strength of the tungsten/rhenium alloy and below the material fatigue limit.
\end{abstract}

\section{A. Introduction}

The next generation of linear colliders require positron beams at greater intensities than in previous collider designs. The NLC positron design' utilizes a wiggler to generate a high energy electron beam. A Tungsten-26\%Rhenium target (4 radiation lengths thick) placed in the path of the beam is used to convert the electrons into positrons.

Peak shock stresses in the target and energy dissipation are major considerations in the design of the target. To avoid excessive heating and to reduce thermal stresses in 
the target, the target is rotated to avoid individual pulses impinging on the same spot on the target. The beam pulses occur 120 times per second and the design goal is to rotate the target to maximize the time before beam pulses overlap on the same region of the target.

The energy deposition in the target is calculated using the EGS4 $4^{2}$ photon energy deposition code. The code calculates the volumetric rate of energy deposition as a function of axial and radial position along the beam trajectory.

The temperature response of the target due to the energy deposition is calculated with the LLNL three-dimensional finite element heat transfer code, Topaz $3 \mathrm{~d}^{3}$. The structural response of the target is calculated with the LLNL finite element dynamic structural analysis code, Dyna $3 \mathrm{~d}^{4}$, which calculates material stress pressure pulses from the thermal expansion of the material.

\section{B. Target Description}

The NLC target, figure 1, consists of a 10 inch $(254 \mathrm{~mm})$ diameter disk of W26Re, four radiation lengths thick $(13 \mathrm{~mm})$, surrounded by an inner wheel of silver material. The target is cyclically rotated during operation in a way that the impinging beam pulses strike a different part of the target after every pulse.

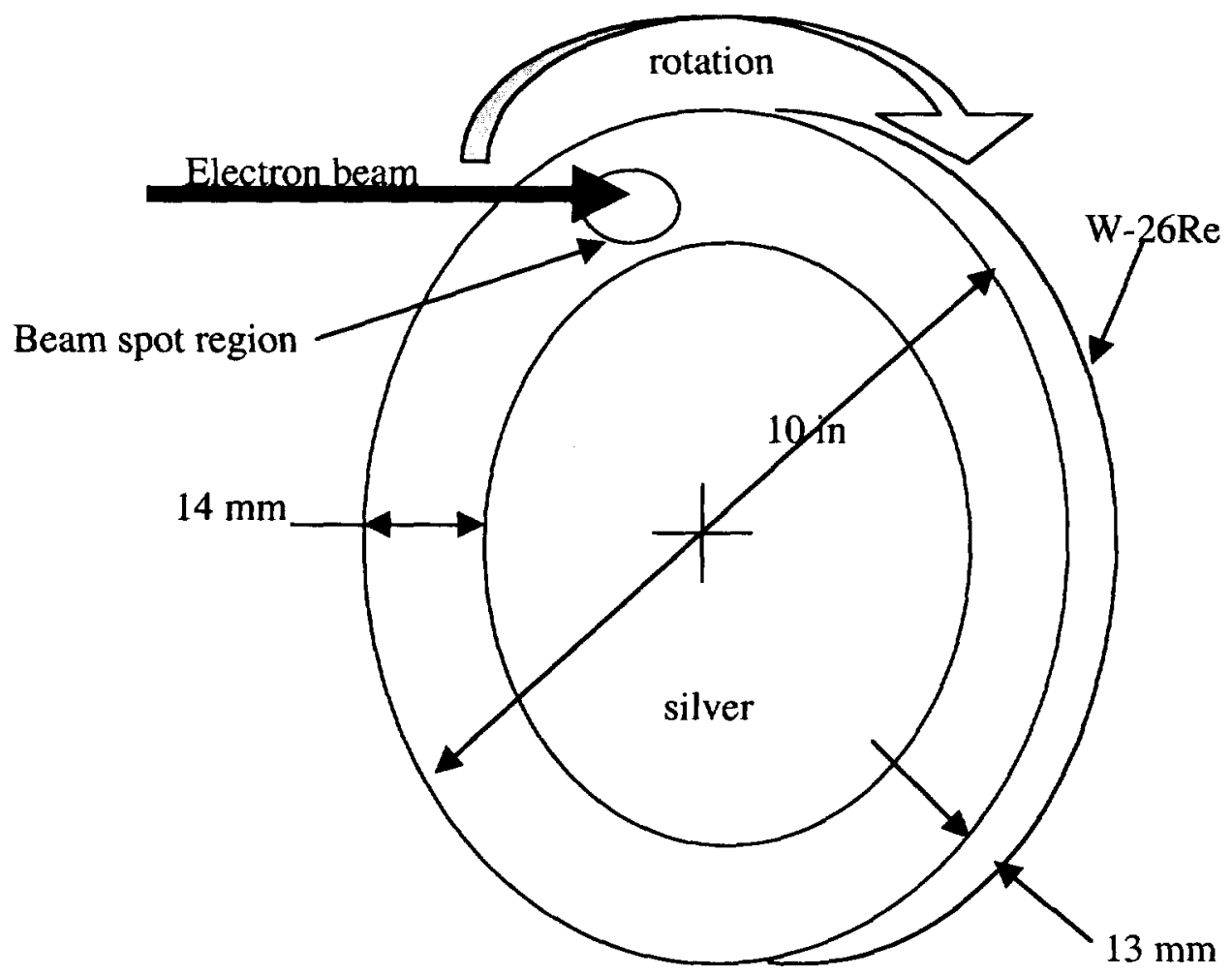

Figure 1. NLC target geometry 
The electron beam impinges on the target approximately $7 \mathrm{~mm}$ from the target outside edge. Each pulse of electrons causes a large increase in temperature in a local spot on the target.

The target is cooled by cooling tubes imbedded in the silver material, and they maintain the tungsten-rhenium target at a nominal $315^{\circ} \mathrm{C}^{5}$. This nominal temperature can be readily decreased by $100^{\circ} \mathrm{C}$ by changes in target size and/or cooling tube arrangement. To avoid ductile/brittle temperature transition problems with the material, a nominal minimum temperature of $200^{\circ} \mathrm{C}$ should be maintained in the target. During daily beam shut down times, some external heating may be required. The individual spots on the target heat up an additional maximum amount of $147^{\circ} \mathrm{C}$ to $462^{\circ} \mathrm{C}$ and relax back down to the $315^{\circ} \mathrm{C}$ temperature before another electron pulse impinges.

The time scales of this problem are such that the target material, where the beam impinges, heats up in 265 nanoseconds and this temperature profile essentially doesn't relax until seconds have elapsed. Thermal stress wave effects are initiated from the nanosecond initial pulse and relax to a steady stress state after several microseconds. After a time period of seconds, however, the spot temperature profile and the thermal stresses have essentially relaxed down to the nominal disc steady state temperature of $315^{\circ} \mathrm{C}$ and a near zero stress state.

\section{Analyses}

The analyses are described in the following steps. The first step consists of defining the beam energy deposition as a function of radial and axial position and time for use in determining the temperature distribution in the target. The second step describes the thermal analyses due to the pulse and the third step describes the transient dynamic structural modeling.

\section{a. Beam energy deposition}

The SLAC EGS4 shower code was used to determine the energy deposition profile ${ }^{6}$. Figure 2 shows the deposition per gram of material profile along the beam centerline into the material for $95 \times 10^{10}$ electrons per bunch. The energy deposition shown in figure 2 has a radial Gaussian profile with a spot radius size of $1.6 \mathrm{~mm}$. The full NLC beam is composed of 190 bunches of electrons per pulse, each bunch is spaced 1.4 nanoseconds apart, with a pulse frequency of 120 pulses per second. Each pulse contains $2.28 \times 10^{12}$ electrons and corresponds to a proportionally larger maximum energy deposition of $125 \mathrm{~J} / \mathrm{g}$ for a $1.6 \mathrm{~mm}$ spot radius beam. For this study, the beam spot radius is assumed to be $3.0 \mathrm{~mm}$ and the number of electrons per pulse are increased to $4.03 \times 10^{12}$ to maintain the required positron yield. The maximum energy deposition occurs on the back side of the targets, along the beam centerline. The average total power deposited by the beam into the three targets is approximately $68 \mathrm{~kW}$. 
For these analyses, the NLC beam is assumed split to impinge on three targets in order to avoid excessive material stresses. The maximum power that can be absorbed by one target is $23 \mathrm{~kW}$, corresponding to $1.34 \times 10^{12}$ electrons per pulse, and the maximum energy deposition is $21 \mathrm{~J} / \mathrm{g}$.

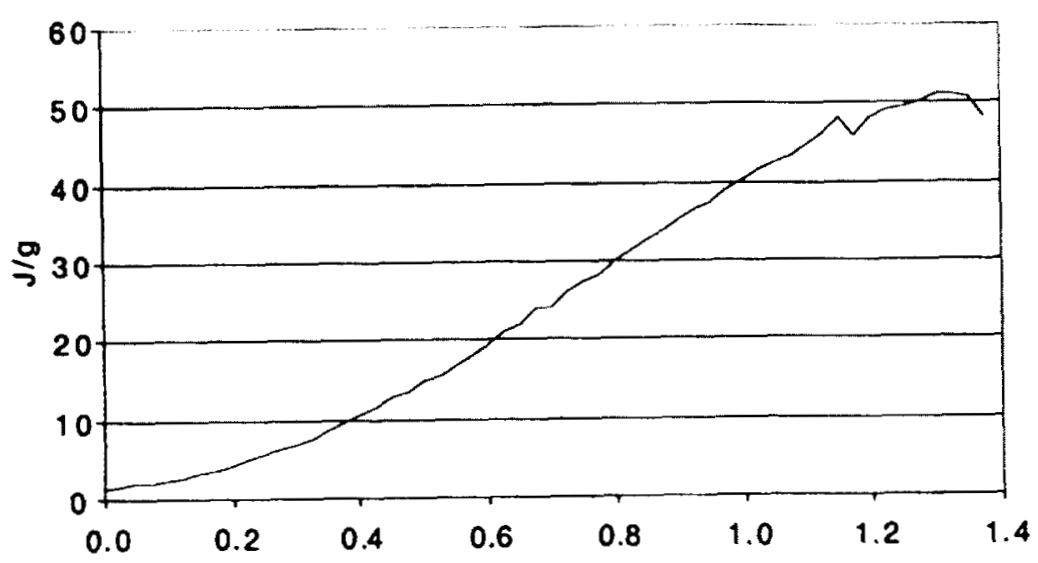

Target depth, $\mathrm{cm}$.

Figure 2. Target energy deposition, $\mathrm{J} / \mathrm{g}$, along beam centerline for $95 \times 10^{+10}$ electrons at $6.2 \mathrm{GeV}, 1.6 \mathrm{~mm}$ sigma radius.

\section{b. Thermal Analyses}

The temperature profile in the target is modeled with an energy per unit volume heat source. The heat source mimics a beam Gaussian radial profile and the axial profile shown in figure 2 (with a maximum energy deposition of $21 \mathrm{~J} / \mathrm{g}$ ).

From material properties, table 1, of density, specific heat, and thermal conductivity and the volumetric energy deposition rate, the temperature of the material is calculated using the LLNL three-dimensional finite element heat transfer code, Topaz3d. The time scale for the energy deposition ( 265 nanoseconds ) is relatively small versus the time for any energy to conduct into the surrounding material. The temperature profile that exists in the material initially after 265 nanoseconds of pulse energy deposition is thus the profile that is used to determine the resultant material thermal stress. Over a time scale of seconds, the temperature and stress relax to low values until another pulse strikes the same region. 
Table 1. Tungsten-26\%Rhenium thermal properties.

\begin{tabular}{|l|c|r|r|}
\hline property & & & \\
\hline Temperature, ${ }^{\circ} \mathrm{C}$ & 0 & 500 & 1000 \\
\hline Density, $\mathrm{Kg} / \mathrm{m}^{3}$ & 19800 & 19800 & 19800 \\
\hline Specific heat, $\mathrm{J} / \mathrm{Kg} /{ }^{\circ} \mathrm{C}$ & 135 & 149 & 165 \\
\hline Thermal conductivity, $\mathrm{W} / \mathrm{m}^{2} /{ }^{\circ} \mathrm{C}$ & 68 & 67 & 66 \\
\hline
\end{tabular}

Figure 3 shows the peak temperatures calculated on the back side of the target from the energy deposited by one pulse. The target peak temperature increases by $147^{\circ} \mathrm{C}$, from an assumed initial temperature of $315^{\circ} \mathrm{C}$ to a spot peak temperature of $462^{\circ} \mathrm{C}$. Figure 4 shows a temperature profile through the target after one electron pulse has deposited its energy in the target.

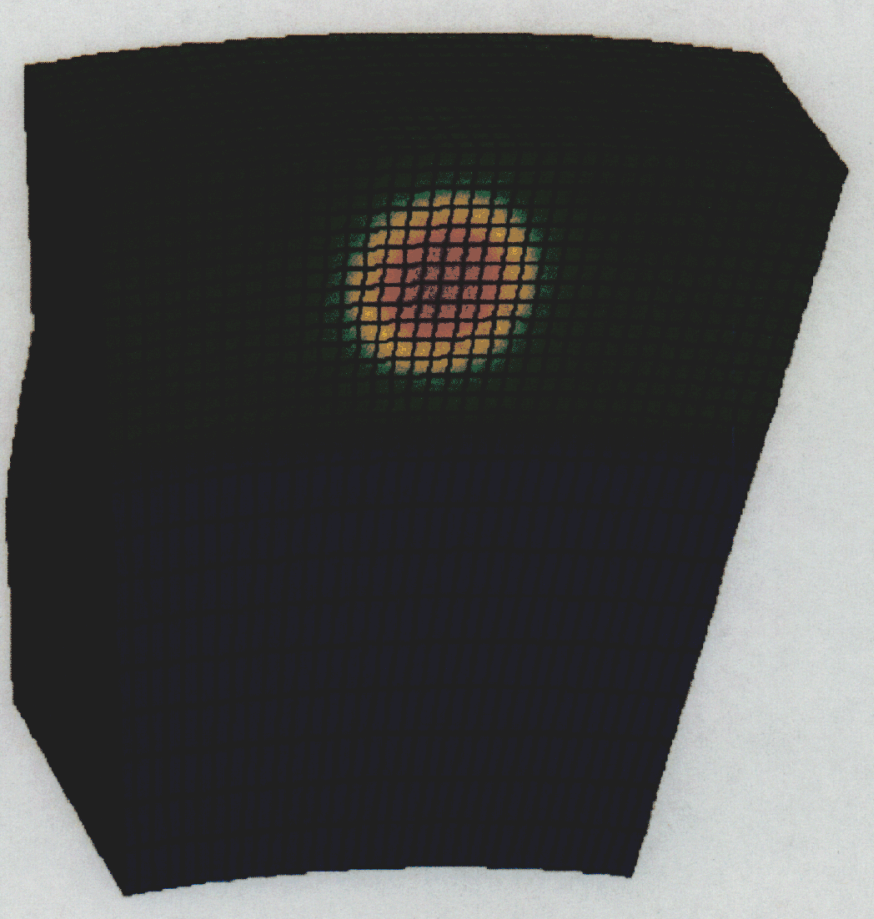

Temperoture

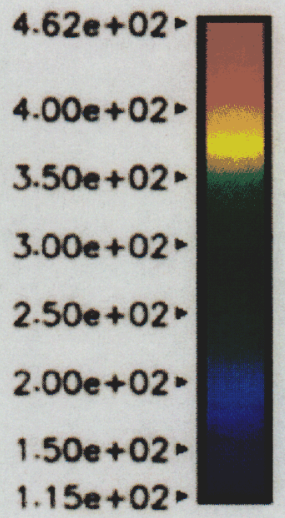

Figure 3. NLC target temperature, ${ }^{\circ} \mathrm{C}$, contour due to the impinging electron beam. 


\section{c. Structural modeling}

The heating of the target results in rapid thermal expansion of the heated target material and pressure pulses traveling out from the heated region. The stresses resulting from the expansion are calculated using the LLNL three-dimensional finite element dynamic structural mechanics code, Dyna3d, with temperature input from the results of the Topaz3d thermal analyses. The Dyna3d code calculates the thermal expansion by use of a coefficient of thermal expansion and a change in target temperature. Stresses are determined from stress and strain relationships for the tungsten/rhenium material.

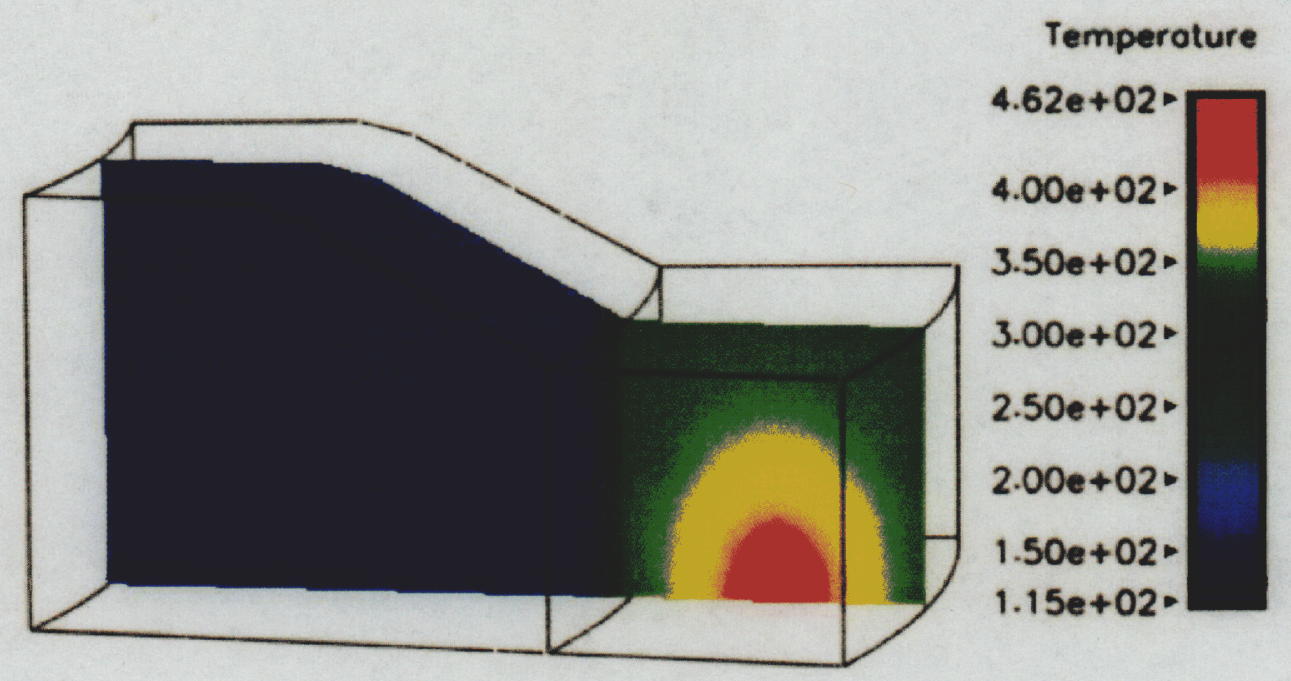

Figure 4. Target temperature, C, cross-section after one beam pulse.

The structural modeling requires developing a calculational mesh of sufficient detail to allow the code to model the physics of the problem. The mesh, shown in figure 3 , models a slice of the target disc, including the silver on the inside region of the tungsten-rhenium disc.

The materials in the problem are modeled with a temperature dependent elasticplastic material model. Properties specified include the elastic modulus, Poisson's ratio, secant coefficient of thermal expansion, yield stress, and plastic modulus. For these analyses, the properties used are shown in table 2.

For these analyses, the structural response of the target to one pulse is so fast, less than several microseconds, that only the thermal shock results for one spot location 
needs to be analyzed. Before a next adjacent spot is impinged upon, $1 / 120$ seconds have elapsed and the previous shock pulses have dissipated and the new spot location does not appreciably affect the adjacent spot temperature or stress state.

Table 2. Tungsten-26 Rhenium material structural properties.

\begin{tabular}{|l|c|c|c|}
\hline Property & & & \\
\hline Temperature & $0.0^{\circ} \mathrm{C}$ & $500.0^{\circ} \mathrm{C}$ & $1000.0^{\circ} \mathrm{C}$ \\
\hline Modulus, $\mathrm{Pa}$ & $4.30 \times 10^{11}$ & $4.02 \times 10^{11}$ & $3.95 \times 10^{11}$ \\
\hline Poisson's ratio & 0.28 & 0.28 & 0.28 \\
\hline $\begin{array}{l}\text { Secant coef. of } \\
\text { thermal exp., } \mathrm{C}^{-1}\end{array}$ & $6.66 \times 10^{-6}$ & $7.06 \times 10^{-6}$ & $7.95 \times 10^{-6}$ \\
\hline Yield stress, $\mathrm{Pa}$ & $1.6 \times 10^{9}$ & $1.25 \times 10^{9}$ & $9.0 \times 10^{8}$ \\
\hline
\end{tabular}

The rapid beam energy deposition results in stresses that are greatest at the target location where the beam shower exits the target. Von Mises stress is a good measure of the proximity to failure of a material with values below material yield stress usually indicating structural integrity.

Figure 5 shows a contour color plot of the peak Von Mises stress attained on the back side of the target at the impinging beam location. The figure shows a peak value of $5.77 \times 10^{8} \mathrm{~Pa}(83 \mathrm{ksi})$ at a time of $5 \times 10^{-7}$ seconds after the beam impinged on the target.

The structural response of the target material due to the rapid heating of the material results in pressure waves propagating out from the beam location. The material initially goes into a relatively high state of compression followed by a tension stress condition. The effective stress response in figure 5 is applicable for the short time during which the target undergoes its highest pressure pulse stress. A plot of Von Mises effective pressure pulse stress at the most severe location on the back side of the target versus time is shown in Figure 6. The pressure waves dissipate after several microseconds and the material goes into a semi-static lower level stress state due to the temperature induced strain in the material, figure 7 , with a maximum effective stress of $25 \mathrm{ksi}\left(1.7 \times 10^{8} \mathrm{~Pa}\right)$. 


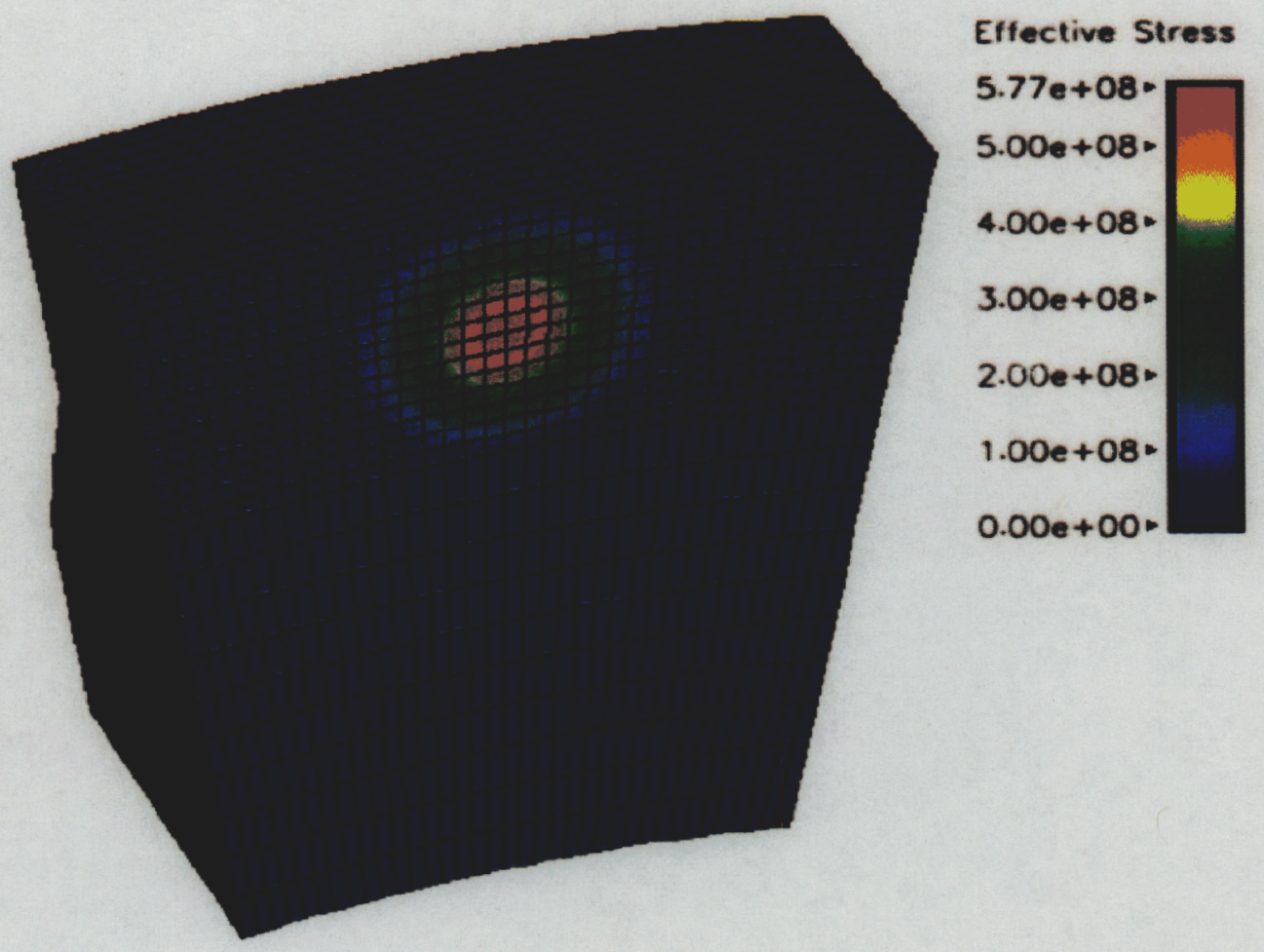

Figure 5. Peak Von Mises stress, $\mathrm{Pa}$, in the target after one pulse.

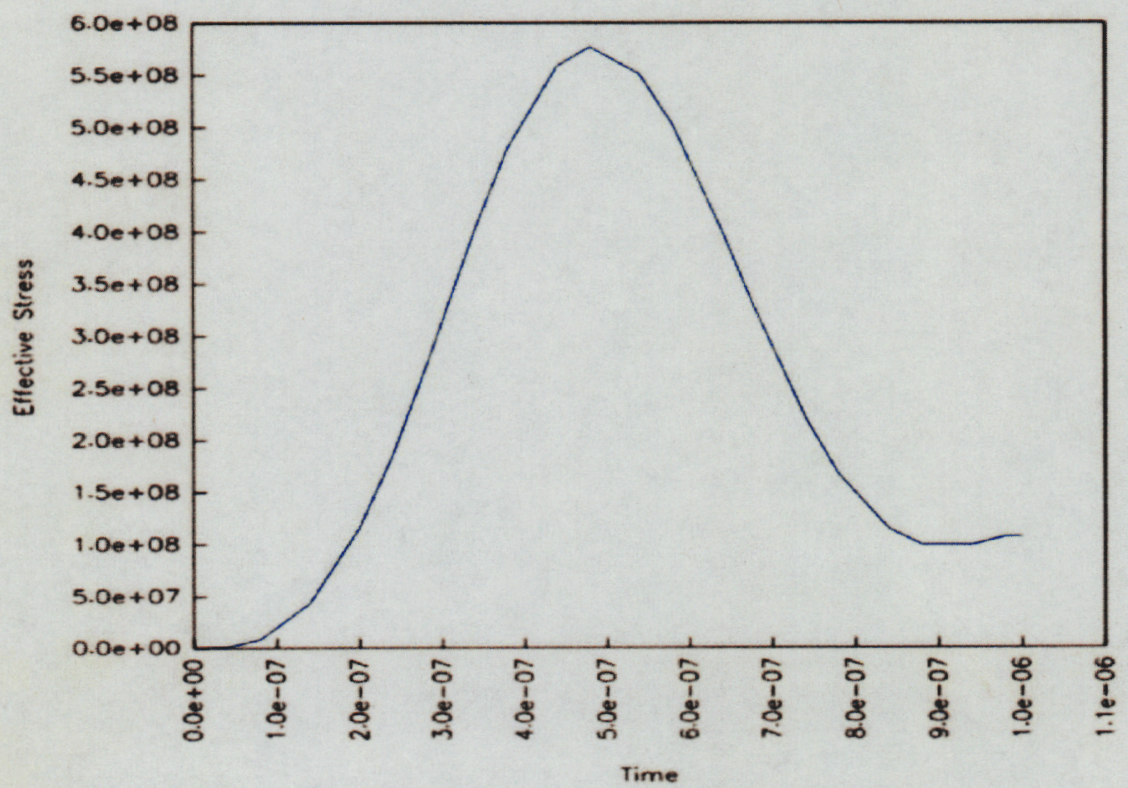

Figure 6. Peak Von Misses stress, $\mathrm{Pa}$, versus time, $\mathrm{s}$, at the beam exit location of the NLC target due to one beam pulse. 


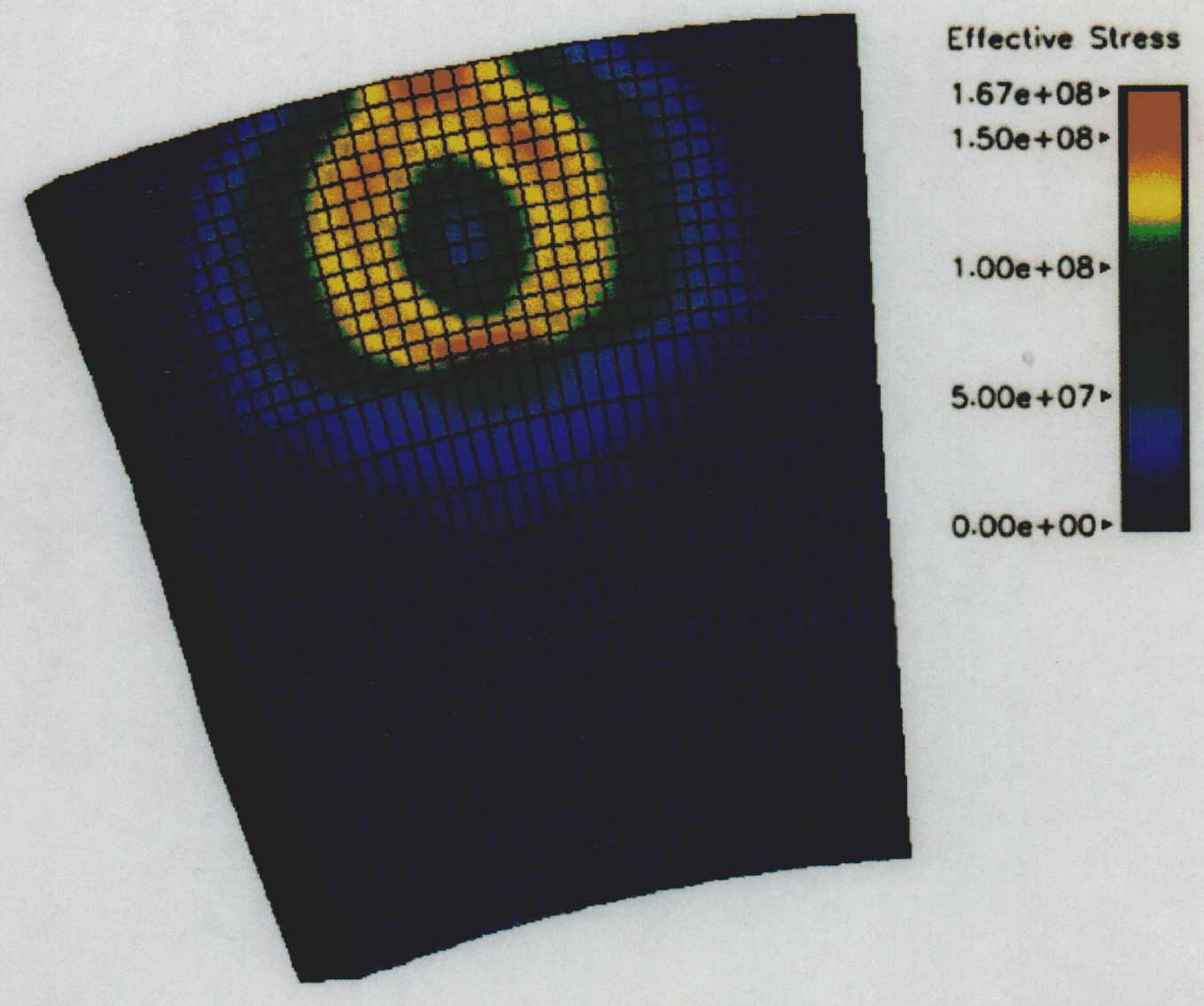

Figure 7. Steady state stress, $\mathrm{Pa}$, in the target due to one beam pulse, after the pressure pulses have relaxed.

\section{Conclusions and discussion}

The thermal structural response of an NLC target due to a $3 \mathrm{~mm}$ spot radius split NLC beam was investigated. The beam was assumed split to impinge on three targets in order to reduce thermal stresses in the individual targets. The analyses showed three targets were required to absorb the full NLC electron beam.

The analyses show that stresses do not exceed material yield stress. Due to the cyclical nature of the beam energy deposition, failure due to material fatigue must also be considered and may occur at stresses below yield. A general criteria of fatigue failure due to a Von Mises stress of $50 \%$ of yield strength may apply to this target material. Preliminary LLNL fatigue failure data, at elevated temperatures, shows a fatigue limit stress near $100 \mathrm{ksi}$. The calculated peak Von Mises stress of $83 \mathrm{ksi}(5.77 \mathrm{e}+08 \mathrm{~Pa})$ is below the fatigue limit yield stress and the target should operate satisfactorily. 
Another concern for the target's successful operation is that radiation damage due to material dislocations will degrade the material structural properties and thus failure occurring due to enhanced brittleness and lower fatigue limits. From a theoretical study of radiation damage ${ }^{7}$ in the NLC and SLC targets, the NLC target may be designed to have a wheel size and rotation speed such that operation for about one year without excessive radiation damage may be possible.

\section{E. References.}

1. Zeroth-Order Design Report for the Next Linear Collider, LLNL internal report, UCRL-ID-124161.

2. W. R. Nelson et al., "The EGS4 Code System", SLAC-Report-265, December 1985.

3. Arthur B. Shapiro, "TOPAZ3D - A three-dimensional finite element heat transfer code", Lawrence Livermore National Laboratory, Livermore, California, UCID20484, August 1985.

4. John O. Hallquist, Robert G. Whirley, "DYNA3D User's Manual”, Lawrence Livermore National Laboratory, Livermore, California, UCID-19592, May 1989.

5. Werner Stein memorandum, "Thermal Analyses of the SLC Positron Target and Proposed NLC Positron Target Designs", Lawrence Livermore National Laboratory, Livermore, California, May 19, 2000.

6. David C. Schultz, et al.,"NLC Positron Target Heating", Stanford Linear Accelerator Center, Stanford, California, LCC-0082, June 19, 2001.

7. Maria J. Caturla, "Radiation damage induced by $\mathrm{GeV}$ electrons in W-Re targets for next generation linear colliders", Lawrence Livermore National Laboratory, Livermore, California, UCRL-JC-148049, May 2002. 